\title{
PICC Your Battles: Considering the Appropriateness of Peripherally Inserted Central Catheter (PICC) Lines for Outpatient Parenteral Antimicrobial Therapy (OPAT) in Injection Drug Users (IDUs)
}

\author{
Maxime Jasmine Billick, $\mathrm{BA}^{1}$
}

${ }^{1}$ Faculty of Medicine, McGill University

\section{A B STRACT}

Injection drug users (IDUs) requiring outpatient parenteral antibiotic therapy (OPAT) for injection-related infections are regularly denied the use of peripherally inserted central catheter (PICC) lines based on the assumption that they will use the port to inject illicit drugs, and that it will be used in a non-sterile/unclean fashion. While IDUs have higher rates of infective endocarditis, abscesses and septicemia, there is no substantial body of evidence that PICC lines in IDUs result in more serious infections, increased overdoses or increased morbidity or mortality. Successful transition of IDUs from inpatient treatment to OPAT requires appropriate patient selection. Namely, housing status, mental health history, the presence of a support system, and a patient's willingness to comply with treatment all play a significant role in OPAT success. Honest and straightforward conversations must be undertaken between patient and provider regarding the risks and benefits of a PICC line if injecting drugs. Close follow-up, a compassionate approach, provider education, and the expansion of respite programs all introduce novel spaces for ongoing harm reduction and good patient care. Finally, further research is needed to establish protocols, guidelines, screening criteria, transition of care, and to clarify best practices for OPAT in patients who inject drugs.

\section{RÉ S U M É}

Les utilisateurs de drogues injectables (UDIs) ayant besoin d'une antibiothérapie par voie parentérale ambulatoire (APA) pour des infections associées aux injections se voient fréquemment refuser l'accès à un cathéter central à insertion périphérique (PICC, de l'anglais) puisqu'on présume qu'ils l'utiliseront pour s'injecter des drogues illicites, et que le cathéter sera utilisé de manière non stérile ou peu hygiénique. Bien que les UDIs présentent des taux plus élevés d'endocardite infectieuse, d'abcès et de septicémie, il n'existe pas de preuves substantielles qui démontrent que les PICCs chez les UDIs entraînent des infections plus sévères, ou une hausse de surdoses, de morbidité ou de mortalité. La transition réussie des UDIs d'un traitement hospitalier vers une APA exige une sélection attentive des patients. Notamment, la situation de logement, les antécédents de santé mentale, la présence d'un système de soutien et la volonté du patient de suivre le traitement contribuent tous au succès de l'APA. Des conversations honnêtes et directes doivent avoir lieu entre le patient et le fournisseur de soins quant aux risques et aux avantages d'un PICC et de l'utilisation de drogues injectables. Un suivi étroit, une approche compatissante, la formation appropriée des fournisseurs de soins, et l'expansion des programmes de répit constituent tous de nouvelles façons de réduire les méfaits et d'améliorer les soins aux patients. Finalement, plus de recherche est nécessaire afin de mettre en place des protocoles, des lignes directrices, des critères de dépistage et des transitions de soins, et pour clarifier les pratiques exemplaires quant à l'APA chez les patients qui utilisent des drogues injectables.

BT lay with her head cocked in the only comfortable position, her thin legs protruding below flimsy hospital sheets. I was on a rotation in Infectious Diseases based at several Toronto-area hospitals and she was not my first intravenous (IV) drug-using patient. She was, however, the first patient I had seen who was unable to move her head more than several millimeters in either direction since a paraspinal abscess precariously abutted her spinal cord.

BT could be argumentative-she had yelled at several nurses and often refused to have her vital signs taken. She also told me she was scared-she recognized that finding herself in this position was likely secondary to her IV drug use. Despite delivering attentive care, some of the nurses rolled their eyes when talking about Keywords: Drug Users; PICC Placement; Abscess; Heroin Dependence; Harm Reduction
BT, and the social worker said that the patient refused her entry into the hospital room because she "didn't like [her] face."

The sentiments I witnessed towards injection drug users (IDUs) are not unique to my clinical rotation. A recent meta-analysis sought to assess health professionals' attitudes regarding patients with substance use disorders and to examine the consequences on healthcare delivery [1]. The analysis revealed that health care workers generally held negative attitudes toward patients with substance use disorders, often taking an avoidant approach to healthcare provision [1]. This resulted in shorter visits, diminished empathy, and lower personal engagement, presumed to result in subpar healthcare delivery [1]. Additionally, 
the negative attitudes of health professionals add a significant barrier to patient recovery, since healthcare workers often play a crucial role in recognizing substance use problems, empowering patients, and acting as gatekeepers to treatment [1].

BT required six weeks of antibiotic therapy, most of which necessitated IV delivery via a peripherally inserted central catheter (PICC) line. Numerous people on her immediate treating team including nurses, attending surgeons, residents, and other consultants were dismayed that an IDU would likely need a semipermanent PICC line.

Tertiary care hospitals throughout Canada arrange outpatient parenteral antimicrobial therapy (OPAT) for patients requiring long-term IV antibiotic delivery. OPAT has demonstrated costeffectiveness benefits when compared to a full in-hospital IV antibiotic treatment course [2]. A recent analysis of a 334-person cohort in the UK estimated a yearly cost of approximately $£ 300,000$ (including pre-clinical set-up costs), whereas the minimum theoretical in-patient cost was more than three times high-

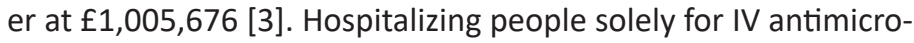
bial treatment is not cost effective. Moreover, an additional bed is occupied, which could be given to a patient in need [3]. Despite this, many physicians continue to believe IDUs should not be discharged with a PICC line under any circumstances [4]. During my clinical training, common beliefs I noted among medical professionals included infection of the line itself, and that the resulting infection would inherently be more serious than one acquired by self-injection. Others surmised that the individual may use the port to inject drugs.

Fundamentally, there is no consensus in the literature that supports these statements. People who use IV drugs do have higher rates of infective endocarditis, abscesses and septicemia [5-7]. However, there is no meaningful body of evidence that PICC lines in IDUs result in more serious infections, increased overdoses, or increased morbidity and mortality. In fact, the few studies that have examined PICC line complications concluded that complication rates were similar amongst IDUs and non-users [8]. Moreover, improvement and recovery rates were high among IDUs with PICC lines (73.3\% cure rate, $23.3 \%$ readmission rate, 3.3\% relapse rate), and no deaths, serious misadventures or line tampering were reported $[9,10]$.

Physicians' own discomfort with discussing IV drug use may be reflected in the paucity of patient-physician conversations. In a study conducted by the National Center on Addiction and Drug Abuse at Columbia University, less than $20 \%$ of primary care doctors described themselves as "very prepared" to identify alcoholism and illegal drug use, and over $50 \%$ of patients with substance use disorders said their primary care physician did not address their substance abuse [11]. Honest and straightforward conver- sations must be held between patients and providers regarding the importance of keeping the PICC line as clean as possible, given its indwelling nature and the increased risk of endocarditis in IDUs. If patients plan or believe they might use the PICC line for injecting drugs, oral antibiotic alternatives may be tried with the understanding that they may be less effective $[6,8,12]$. Patients can also be encouraged to inject more safely by cleaning the site adequately, using sterile water to mix with their drugs, using new needles each time, and not sharing paraphernalia [13]. Additionally, appointments with patients at one-week intervals, repeat blood tests and cultures, and close follow-up for symptoms or signs of infection is essential (Dr. Isaac Bogoch MD MPH, personal communication, October 18, 2016). Ultimately, the goal of the treatment is not to cure someone of their substance use disorder, but rather to cure their infection and act as a liaison to further care should the patient desire.

Successful transition of IDUs from inpatient treatment to OPAT has been documented in several case reports and studies, however effective transition requires careful patient selection $[10,14]$. Ho et al. demonstrated that patients stratified by predefined criteria can be safely and successfully treated with OPAT [10]. Patients signed a contract asserting they would comply with daily OPAT visits, they would not access the PICC line for drug injection, and they would not take drugs unless prescribed by a hospital physician [10]. Formal drug counselling was provided at the onset and as needed [10]. Intermittent IV drug use was not a definite dismissal from the program as long as the PICC line was not used [10]. PICC lines were inspected by nurses for breach of security seals (stickers) prior to antibiotic administration [10]. With these conditions in place, the investigators obtained similar rates of readmission and PICC line infections between IDUs and non-IDUs [10].

More recently, the importance of appropriate patient selection for OPAT was also highlighted by Beieler et al [14]. The investigators examined the implementation of OPAT at a medical respite facility and found that rates of adverse events with IDUs (13\%) were similar to that of non-IDUs (3-10\%), and the readmission rate of IDUs was comparable to current literature of non-IDUs (30\% compared to $9-26 \%$, respectively) [14]. The investigators partially attributed OPAT success to the close examination of patients' social behaviours throughout the selection process [14]. Notably, IV drug use alone may be not be reflective of future OPAT success or failure. Rather, housing status, mental health history, the presence of a support system and a patient's willingness to comply with treatment all play a significant role [14-16].

The balance between patient autonomy and physician benevolence may appear tenuous when considering candidates for OPAT who inject drugs. Nonetheless, healthcare providers must provide adequate information and support to IDUs with the capacity 


\section{Commentary}

to consent in order to help them to make informed decisions. Care must be tailored to the individual; some IV drug users may be appropriate and reliable candidates for OPAT, while others may not be. In addition to appropriate patient selection when considering IDUs requiring OPAT, close follow-up, a compassionate approach, provider education, and expansion of respite programs all introduce novel spaces for ongoing harm reduction and good patient care. Further research is needed to clarify best practices regarding OPAT for IDUs, and to establish screening criteria and guidelines for treatment in this population.

\section{ACKNOWLEDGEMENTS}

I would like to thank Dr. Isaac Bogoch for his guidance and support during both the clinical component and writing process of this manuscript, and Marta Cybulsky for her ongoing feedback.

\section{REFERENCES}

1. van Boekel LC, Brouwers EPM, van Weeghel J, Garretsen HFL. Stigma among health professionals towards patients with substance use disorders and its consequences for healthcare delivery: Systematic review. Drug Alcohol Depend. 2013;131(1-2):23-35.

2. Wai AO, Frighetto L, Marra CA, Chan E, Jewesson PJ. Cost analysis of an adult outpatient parenteral antibiotic therapy (OPAT) programme. A Canadian teaching hospital and Ministry of Health perspective. PharmacoEconomics. 2000;18(5):451-7.

3. Chapman ALN, Dixon S, Andrews D, Lille PJ, Bazaz R, Patchett JD. Clinical efficacy and cost-effectiveness of outpatient parenteral antibiotic therapy (OPAT): a UK perspective. J Antimicrob Chemother. 2009; 64(6):1316-24.

4. Mallon WK. Is it acceptable to discharge a heroin user with an intravenous line to complete his antibiotic therapy for cellulitis at home under a nurse's supervision?: No: A home central line is too hazardous. West J Med. 2001;174(3):157.

5. Hussey $\mathrm{HH}$, Katz S. Infections resulting from narcotic addiction: Report of 102 cases. Am J Med. 1950;9(2):186-93.

6. Del Giudice P. Cutaneous Complications of Intravenous Drug Abuse. Br J Dermatol. 2004;250(1):1-10.

7. Management of Common Health Problems of Drug Users. New Delhi, India. World Health Organization, Regional Office for South-East Asia; 2009. 132 p. Technicla Publication Series No. 56. Available from: http://www.who.int/ hiv/topics/idu/drug_dependence/hiv_primary_care guidelines searo.pdf.

8. Hill A, Wai A, Marsh D, Stiver HG, Sakakibara T. Pilot assessment of Intravenous Antibiotic Therapy in a Live-in Street-based Clinic, for Infections in Intravenous Drug Users (IVDU's). Poster Presentation Abstract at IDWeek. 44th Annual Meeting of the Infectious Diseases Society of America; 2006 Oct 13. Available from: https://idsa.confex.com/idsa/2006/webprogram/ Paper22373.html.

9. Papalekas E, Patel N, Neph A, Moreno D, Zervos M, Reyes KC. Outpatient Parenteral Antimicrobial Therapy (OPAT) in Intravenous Drug Users (IVDUs): Epidemiology and Outcomes. Poster Presentation Abstract at IDWeek. 52nd Annual Meeting of the Infectious Diseases Society of America; 2014 Oct 11. Available from: https://idsa.confex.com/idsa/2014/webprogram/Paper46252.html.

10. Ho J, Archuleta J, Sulaiman Z, Fisher D. Safe and successful treatment of intravenous drug users with a peripherally inserted central catheter in an outpatient parenteral antibiotic treatment service. J Antimicrob Chemother. 2010;65(12):2641-44.

11. Missed Opportunity: National Survey of Primary Care Physicians and Patients on Substance Abuse. New York (NY). The National Center on Addiction and Substance Abuse at Columbia University. 2000 May. 105 p. Available from: http://www.casacolumbia.org/templates/publications_reports.aspx.

12. Al-Omari A, Cameron DW, Lee C, Corrales-Medina VF. Oral antibiotic therapy for the treatment of infective endocarditis: a systematic review. BMC Infect
Dis. $2014 ; 13(14): 140$

13. Kidorf M, King VL. Expanding the Public Health Benefits of Syringe Exchange Programs. Can J Psychiat. 2008;53(8):487-95.

14. Beieler AM, Dellit TH, Chan JD, et al. Successful Implementation of Outpatient Parenteral Antimicrobial Therapy at a Medical Respite Facility for Homeless Patients. J Hosp Med. 2016;11(8):531-5.

15. Bartlett R, Brown L, Shattell M, Wright T, Lewallen L. Harm Reduction: Compassionate Care Of Persons with Addictions. Medsurg Nurs. 2013;22(6):34958.

16. Libertin CR, Camsari UM, Hellinger WC, Schneekloth TD, Rummans TA. The cost of a recalcitrant intravenous drug user with serial cases of endocarditis: Need for guidelines to improve the continuum of care. IDCases. 2017;8:3-8. 